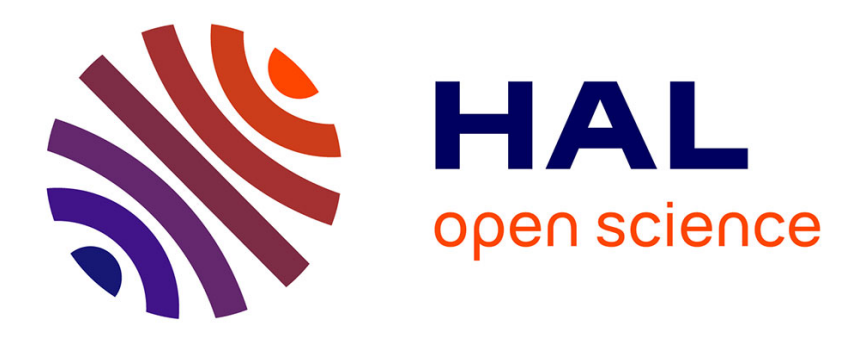

\title{
Pressure effects on radiative heat transfer in sooting turbulent diffusion flames
}

Fatiha Nmira, Y Liu, Jean-Louis Consalvi, Frédéric André, Franklin Liu

\section{To cite this version:}

Fatiha Nmira, Y Liu, Jean-Louis Consalvi, Frédéric André, Franklin Liu. Pressure effects on radiative heat transfer in sooting turbulent diffusion flames. Journal of Quantitative Spectroscopy and Radiative Transfer, 2020, 245 (106906), 10.1016/j.jqsrt.2020.106906 . hal-02971328

\section{HAL Id: hal-02971328 \\ https://hal.science/hal-02971328}

Submitted on 28 Apr 2021

HAL is a multi-disciplinary open access archive for the deposit and dissemination of scientific research documents, whether they are published or not. The documents may come from teaching and research institutions in France or abroad, or from public or private research centers.
L'archive ouverte pluridisciplinaire HAL, est destinée au dépôt et à la diffusion de documents scientifiques de niveau recherche, publiés ou non, émanant des établissements d'enseignement et de recherche français ou étrangers, des laboratoires publics ou privés. 


\title{
PRESSURE EFFECTS ON RADIATIVE HEAT TRANSFER IN SOOTING TURBULENT DIFFUSION FLAMES
}

\author{
Fatiha Nmira ${ }^{1}$, Yuying Liu ${ }^{2}$, Jean-Louis Consalvi ${ }^{3, \dagger}$, Frederic Andre ${ }^{4}$, Fengshan Liu $^{5}$ \\ ${ }^{1}$ Direction R\&D EDF, 6 quai Watier, 78400 Chatou, France. \\ ${ }^{2}$ School of Energy and Power Engineering, Beihang University (BUAA), Beijing, 100191, China \\ ${ }^{3}$ Aix-Marseille Université, IUSTI/ UMR CNRS 7343, 5 rue E. Fermi, 13453 Marseille, France. \\ ${ }^{4}$ Univ Lyon, CNRS, INSA-Lyon, Université Claude Bernard Lyon 1, CETHIL UMR5008, F-69621 Villeurbanne, \\ France. \\ ${ }^{5}$ Metrology Research Centre, National Research Council of Canada, 1200 Montreal Road, Ottawa, Ontario K1A 0R6, \\ Canada \\ † Corresponding author: Tel.: +33-491-106-831; Fax: +33-491-106-969. \\ E-mail address: jean-louis.consalvi@univ-amu.fr
}

\begin{abstract}
.
This article investigates the effects of increasing pressure up to 4 atm on radiative heat transfer in momentum-driven methane turbulent jet flames by using well-established chemical mechanism, combustion, soot production and radiation models. A transported PDF method is used to close properly the soot-production turbulence interaction and the emission Turbulence Radiation Interaction (TRI). A Narrow-Band CK (NBCK) model is used as the gas radiative property model. The absorption TRI is neglected based on the Optically-Thin Fluctuation Approximation (OTFA). In accordance with a previous study dealing with non-sooting hydrogen flames (Nmira et al., JQSRT 220 (2018) 172-179), the 3-atm and 4-atm flames are designed from the atmospheric flame by using a Froude modeling approach that allows to preserve the flame/flow structure as the pressure is increased and hence to isolate the pressure effects on soot production, radiative heat transfer, and TRI. The effects of increasing pressure on radiant fraction result from two competing mechanisms: i) an increase in soot emission that
\end{abstract}


tends to increase the radiant fraction and ii) a reduction in flame transparency that tends to reduce it. For the present flames, the first mechanism dominates the second, resulting in an increased radiant fraction with increasing the pressure. The TRI effects on flame radiative loss are also governed by competing mechanisms. The enhancement mechanism is due to gas emission TRI and temperature self-correlation effects on soot emission whereas the reduction mechanism is caused by the negative correlation between soot volume fraction and temperature. The former dominates whereas the latter becomes increasingly important with increasing the pressure. This limits the increase in the global radiative loss due to TRI as the pressure is increased. In addition, numerical simulations show that the TRI effects can reduce the local radiative loss in regions of high soot concentration of the 4 atm flame.

Key Words: methane turbulent jet diffusion flame, pressure effects, radiative loss, turbulenceradiation interaction.

\section{Nomenclature}

\begin{tabular}{|c|c|}
\hline$C_{f_{S} T}$ & cross-correlation between soot volume fraction and temperature [-] \\
\hline$d_{F}$ & inner burner diameter $[\mathrm{m}]$ \\
\hline$F_{r}$ & Froude number [-] \\
\hline$f_{S}$ & soot volume fraction $[-]$ \\
\hline$f_{S, E Q}$ & equivalent soot volume fraction $[-]$ \\
\hline$G_{\eta}$ & incident radiation per unit wavenumber $\left[\mathrm{W} \cdot \mathrm{m}^{-1}\right]$ \\
\hline$h$ & enthalpy $[\mathrm{J} / \mathrm{kg}]$ \\
\hline$I_{b}$ & spectrally-integrated blackbody intensity $\left[\mathrm{W} \mathrm{m}^{-2}\right]$ \\
\hline$I_{b \eta}$ & blackbody intensity at wavenumber $\eta\left[\mathrm{W} \mathrm{m}^{-1}\right]$ \\
\hline$k$ & turbulent kinetic energy $\left[\mathrm{m}^{2} \mathrm{~s}^{-2}\right]$ \\
\hline$L_{f l}$ & flame height $[\mathrm{m}]$ \\
\hline
\end{tabular}




\begin{tabular}{|c|c|}
\hline$l_{e}$ & turbulent integral length scale $[\mathrm{m}]$ \\
\hline$N_{S}$ & soot number density $\left[\mathrm{m}^{-3}\right]$ \\
\hline$\dot{Q}_{C}$ & heat release rate $[\mathrm{W}]$ \\
\hline$\dot{Q}_{a b s}$ & total absorption $[\mathrm{W}]$ \\
\hline$\dot{Q}_{\text {em }}$ & total emission $[\mathrm{W}]$ \\
\hline$\dot{Q}_{e m}^{\prime \prime \prime}$ & total emission per unit flame volume $\left[\mathrm{W} \mathrm{m}^{-3}\right]$ \\
\hline$\dot{Q}_{e m, G}^{\prime \prime \prime}$ & gas emission per unit flame volume $\left[\mathrm{W} \mathrm{m}^{-3}\right]$ \\
\hline$\dot{Q}_{e m, S}^{\prime \prime \prime}$ & soot emission per unit flame volume $\left[\mathrm{W} \mathrm{m}^{-3}\right]$ \\
\hline$r$ & radial coordinate $[\mathrm{m}]$ \\
\hline$t_{\text {res }}$ & residence time of the fuel in the flame envelop [s] \\
\hline$t_{\text {Kol }}$ & Kolmogorov time scale $[\mathrm{s}]$ \\
\hline$T$ & temperature $[\mathrm{K}]$ \\
\hline$u_{F}$ & fuel injection velocity $\left[\mathrm{m} \cdot \mathrm{s}^{-1}\right]$ \\
\hline$V_{f l}$ & flame volume $\left[\mathrm{m}^{3}\right]$ \\
\hline$W_{f l}$ & flame width $[\mathrm{m}]$ \\
\hline$X_{R}$ & enthalpy defect $[\mathrm{J} / \mathrm{kg}]$ \\
\hline$Y_{S}$ & Soot mass fraction $[-]$ \\
\hline$z$ & axial coordinate $[\mathrm{m}]$ \\
\hline$Z_{s t}$ & stoichiometric mixture fraction [-] \\
\hline$\chi$ & scalar dissipation rate $\left[\mathrm{s}^{-1}\right]$ \\
\hline$\chi_{R}$ & radiant fraction $[-]$ \\
\hline$\Delta h_{c}$ & heat of combustion $\left[\mathrm{J} \mathrm{kg}^{-1}\right]$ \\
\hline$\varepsilon$ & dissipation rate of the turbulent kinetic energy $\left[\mathrm{m}^{2} \cdot \mathrm{s}^{-3}\right]$ \\
\hline$\zeta$ & mixture fraction $[-]$ \\
\hline$\eta$ & wavenumber $\left[\mathrm{cm}^{-1}\right]$ \\
\hline
\end{tabular}




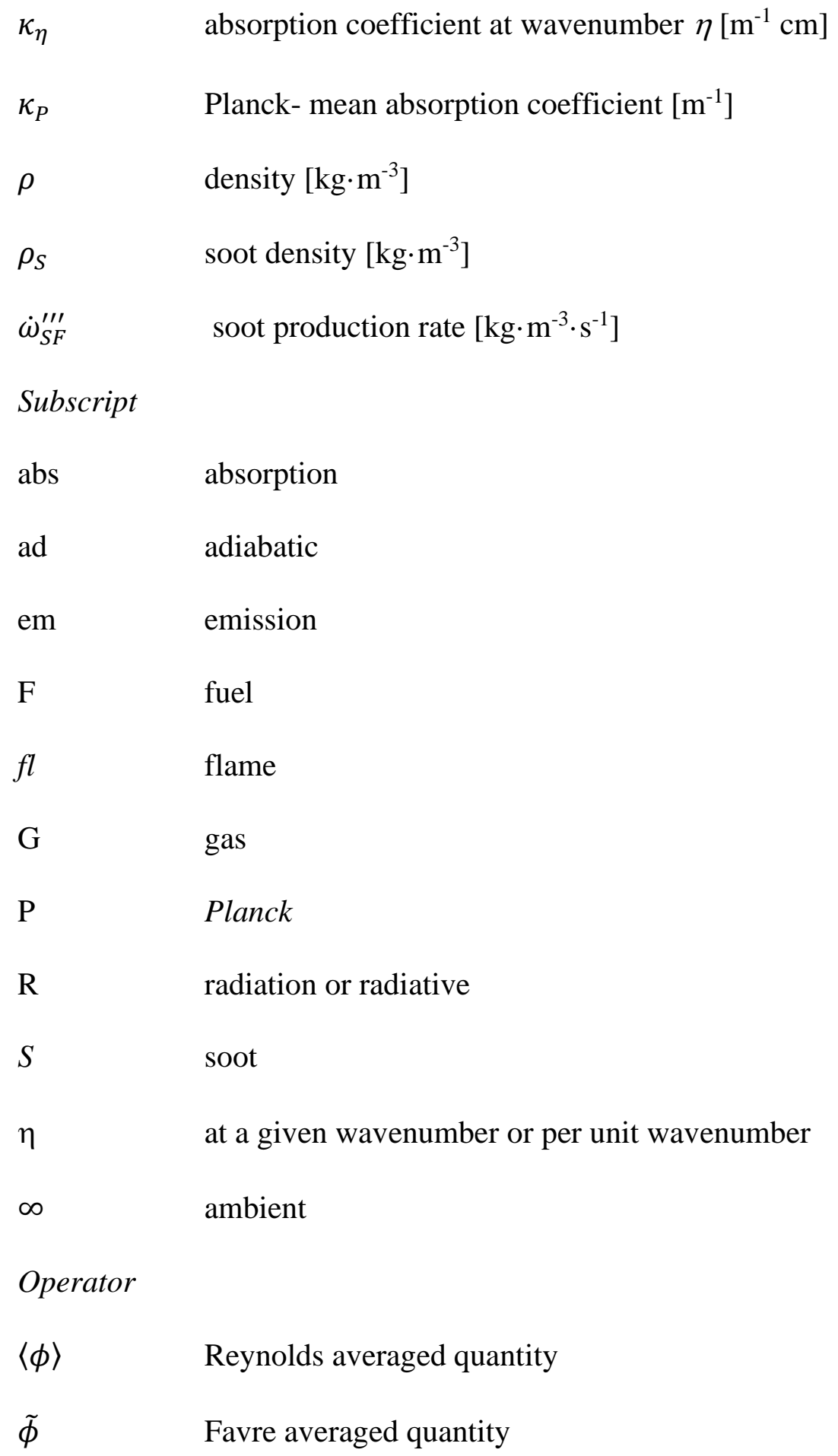

\section{Introduction}

Many practical combustion systems, such as gas turbine combustors and piston engines, involve turbulent sooting flames and operate at elevated pressures for reasons of optimal efficiency and small size. Increasing the pressure affects the flow structure and the chemical reaction rates [1]. 
It modifies also the radiative properties of the medium. Pressure affects gas radiation through enhancements in both gas density and line broadening [1-4]. Calculations made in 1D parallel plate geometry containing mixtures of $\mathrm{CO}_{2}$ and $\mathrm{H}_{2} \mathrm{O}$ representative of oxy-combustion showed that the first mechanism is predominant whereas the second, although significant, has a smaller influence on radiative heat transfer (RHT) [4]. Previous studies also showed that k-distribution methods and the mixing model developed in Ref. [5] can be extended to high pressure gas mixtures $[2-4,6]$. The radiative property of soot is also influenced by pressure rise primarily through an enhancement in soot production and a change in soot volume fraction distribution. Experimental investigations in laminar axisymmetric coflow diffusion flames revealed that soot production scales as $P^{n}$ with $n$ varying on the whole between 1 and 3 , depending on both the fuel and pressure range [7-9].

Most of the studies related to the radiative structure of turbulent diffusion flames including the Turbulent-Radiation Interaction (TRI) effects were performed at atmospheric pressure [1, 1011] and very few studies were devoted to the pressure effects on RHT and TRI. Cai et al. [12] compared a radiative model based on the Full Spectrum Correlated-k (FSCK) model coupled to spherical harmonics methods to a photon Monte Carlo method coupled with a line-by-line spectral model (PMC/LBL) in laminar hydrogen/air diffusion flames at pressures of 1, 5 and 30 atm. They found that the optically-thin approximation is not valid at high pressures and the first order spherical harmonic method $\left(\mathrm{P}_{1}\right)$ is adequate except at very high pressures. Some other recent studies investigated RHT in high-pressure environments relevant to piston engines. FerreyroFernandez et al. [13] investigated numerically RHT in a high-pressure spray flame fueled with n-dodecane by using a transported PDF and PMC/LBL model. They showed that the redistribution of energy is dominated by $\mathrm{CO}_{2}$ and $\mathrm{H}_{2} \mathrm{O}$ is mainly responsible for the radiative heat loss. These findings were used in another work to propose a computationally efficient 
stepwise-gray model that provides predictions within $10 \%$ deviations from the results of accurate spectral radiation models [14].

Investigating the pressure effects on a given process is a difficult task, since modifying the pressure may affect the flow characteristics and, therefore, lead to a misleading interpretation. It is therefore desirable to isolate the pressure effects on the investigated process. As an example, such kind of methodology was applied to investigate experimentally the pressure effects on soot production in laminar coflow diffusion flames. The experimental conditions were designed to maintain the flow residence time, which is recognized to affect significantly soot production, unchanged as the pressure is increased, allowing to isolate the pressure effects on soot production [8]. In the framework of turbulent diffusion flames, RHT and TRI are mainly controlled by the flow residence time, flame geometry and turbulent intensity. In a previous study, it was shown numerically that the Froude modelling analysis, which maintains the Froude number constant as the pressure varies, preserves these quantities [15]. The Froude modelling method was applied to investigate the pressure effects on RHT and TRI in 'non-luminous' hydrogen flames. The numerical results showed that the increase in radiative loss with increasing pressure is limited by an enhancement in the flame optical thickness. It was also shown that the TRI effects on radiative losses are on the whole enhanced by pressure rise.

The objective of this study is to investigate the effects of increasing pressure on RHT and TRI in turbulent sooting diffusion flames. To isolate the pressure effects, the flames at elevated pressures were designed from the atmospheric counterpart by using the Froude modeling strategy reported in Ref. [15].

\section{Numerical model}


The turbulent jet diffusion flames are modelled by using the computational model described in detail in Refs. [16-18]. A brief description is given below.

The model is based on a hybrid flamelet/transported composition PDF approach. The local thermochemical properties of a reactive flow is determined by a set of scalar variables, namely the mixture fraction, $\zeta$, the enthalpy defect, $X_{R}=h-h_{a d}$, the scalar dissipation rate, $\chi$, the soot mass fraction, $Y_{S}$, and the soot number density, $N_{S}$. The scalar dissipation rate $\chi$ is assumed to be statistically independent of the other scalars and its PDF is modeled by a Dirac- $\delta$ function. The one-point, one-time joint composition PDF of $\zeta, X_{R}, Y_{S}$ and $N_{S}$ is then transported. The interaction by exchange with the mean (IEM) model is used to model the molecular mixing for mixture fraction and enthalpy defect. On the other hand, the effective Schmidt number for soot is very high and soot is not effectively transported by molecular species. As a consequence the soot scalars are not mixed. The flamelet libraries are generated using the full chemical kinetic scheme of Qin et al. [19]. Soot production is modelled by a semi-empirical acetylene/benzenebased soot model [20]. Turbulence soot interaction (TSI) is modelled 'exactly' by the joint composition PDF.

A time marching technique is used until a statistically stationary state is reached. The conservation equations for momentum, turbulent kinetic energy and the dissipation rate of turbulent kinetic energy are solved in cylindrical coordinates using a finite-volume method on a staggered grid. For the convective terms, the third-order upwind QUICK combined with ULTRASHARP limiter [21]. A second-order central difference scheme is used for diffusion terms. Pressure-velocity coupling is solved using the Iterative PISO algorithm [22]. The joint composition PDF transport equation was solved by using the Stochastic Eulerian Field (SEF) method developed by Valiño [23]. 
Absorption TRI is neglected based on the OTFA. Previous studies showed the validity of OTFA over a broad range of configurations including very large highly-sooting jet fires $[24,25]$ and non-luminous turbulent jet diffusion flames with pressures up to $30 \mathrm{~atm}$ [15]. Emission TRI is modelled 'exactly' by using the joint composition PDF. The spectral gas and soot radiation is modelled using a NBCK. The NB soot absorption coefficient is computed from the Rayleigh theory coupled to the correlations of Ref. [26] for the refractive index. The gas radiation model considers a database of mixed NB k-g distributions generated from the Line-By-Line database of Pearson et al. [27]. The mixing scheme of Modest and Riazzi [5] is used to deal with the mixtures of $\mathrm{CO}_{2}$ and $\mathrm{H}_{2} \mathrm{O}$. For each pressure of interest, the mixed NB k-g distributions are stored in the database for the 10-Gauss quadrature points used to solve the NB Radiative Transfer Equation (RTE), 9 mole fractions of $\mathrm{CO}_{2}$ and 9 mole fractions of $\mathrm{H}_{2} \mathrm{O}, x_{\mathrm{CO} 2}$ and $x_{\mathrm{H} 2 \mathrm{O}}$, ranging from 0 to $1(0,0.05,0.1,0.2,0.3,0.4,0.6,0.8,1), 28$ temperatures, $T$, ranging from 300 to $3000 \mathrm{~K}$ (with a uniform step of $100 \mathrm{~K}$ ), and $115 \mathrm{NBs}$ with a non-uniform spectral resolution optimized to minimize the variation of the blackbody intensity over a NB. At each computational node and for each NB and quadrature point, the gas absorption coefficient is extracted from the database by using a linear interpolation with respect to $x_{\mathrm{CO} 2}$ and $x_{\mathrm{H} 2 \mathrm{O}}$ and a spline interpolation on $T$. For each NB band, the NB soot absorption coefficient is then added to the interpolated gas absorption coefficient. The RTE is solved by the Finite Volume Method (FVM) using the mapping technique developed by Chui et al. [28] for axisymmetric configurations. Computations are carried out using the first-order UPWIND spatial discretization scheme and an angular mesh with $12 \times 16$ control angles.

The capability of the numerical model described above to predict the flame structures, soot production, and RHT was extensively validated in Refs. [16-18] by considering axisymmetric turbulent jet diffusion flames covering wide ranges of turbulence level, residence time, fuel sooting propensity, oxygen index and pressure. In particular, this validation exercise has 
considered the methane turbulent jet diffusion flames at 1 and 3 atm investigated experimentally by Brookes and Moss [29] and the predictions were found to be in satisfactory agreement with the experimental data [16], showing the capability of the numerical method to predict accurately the effects of moderate increase in pressure on the flame structure and soot production. As a consequence, the present study is limited to methane and to a pressure range of 1-4 atm. Another reason to limit the range in pressure at 4 atm is that the Froude modeling may not preserve fully the flame structure if the pressure would be further increased (see section 3.2).

\section{Results and discussions}

\subsection{Radiant fraction}

The radiant fraction, $\chi_{R}$, which represents the fraction of the heat release rate (HRR) that is lost from the flame by thermal radiation, is a relevant metric to quantify the radiative loss from diffusion flames. It is defined as:

$$
\chi_{R}=\frac{\dot{Q}_{e m}-\dot{Q}_{a b s}}{\dot{Q}_{c h}}
$$

where $\dot{Q}_{e m}=\int_{V} 4 \pi\left\langle\kappa_{p} I_{b}\right\rangle d V, \dot{Q}_{a b s}=\int_{V} \int_{\eta} \kappa_{\eta} G_{\eta} d \eta d V$, and $\dot{Q}_{c h}=\rho_{F} u_{F} \pi d_{F}^{2} / 4 \Delta h_{c}$ represent the total emission, the total absorption and the chemical HRR due to combustion, respectively.

Eq. 1 can be rearranged to yield [30]:

$$
\chi_{R}=\frac{4 V_{f l}}{\pi u_{F} d_{F}^{2}} \cdot \underbrace{\frac{\dot{Q}_{e m}^{\prime \prime \prime}}{\rho_{F} \Delta h_{c}}}_{I I} \cdot \underbrace{\left(1-\frac{\dot{Q}_{a b s}}{\dot{Q}_{e m}}\right)}_{I I I}
$$

where $V_{f l}$ is the flame volume and $\dot{Q}_{e m}^{\prime \prime \prime}=\dot{Q}_{e m} / V_{f l}$ is the emission per unit flame volume. Term I represents a global residence time [31], Term II is the inverse of a characteristic emission time 
scale, and Term III characterizes the flame transparency with $\dot{Q}_{a b s} / \dot{Q}_{e m}$ being a measure of the flame optical thickness.

\subsection{High-pressure flame design}

The baseline case is a turbulent coflow methane/air diffusion flame at atmospheric pressure with the operating conditions given in Table 1 . The nozzle diameter and the fuel injection velocity are $2.5 \mathrm{~mm}$ and $133 \mathrm{~m} / \mathrm{s}$, respectively. The injection Reynolds number is 18790 . The Froude number is defined as [32]:

$$
\mathrm{Fr}=\mathrm{u}_{\mathrm{F}} \mathrm{Z}_{\mathrm{st}}^{1.5} /\left[\left(\frac{\rho_{\mathrm{F}}}{\rho_{\infty}}\right)^{0.25}\left(\frac{\mathrm{T}_{\mathrm{ad}}-\mathrm{T}_{\infty}}{\mathrm{T}_{\infty}} \mathrm{gd}_{\mathrm{F}}\right)^{0.5}\right]
$$

The baseline flame is in the momentum-dominated regime, since its Froude number is higher than 5 [32] (see Table 1). In this regime, the flame length is directly proportional to the injection nozzle diameter and can be expressed as [32]:

$$
L_{f l}=\frac{L^{*} d_{F}\left(\rho_{F} / \rho_{\infty}\right)^{1 / 2}}{Z_{s t}} \text { with } L^{*}=23
$$

Eq. 3 shows that maintaining the fuel injection velocity and nozzle diameter constant at an elevated $P$ allows to preserve the Froude number since the adiabatic temperature is very weakly dependent on pressure. Eq. 4 shows that the flame length is then also preserved. A dimensional analysis supports that the flame structure is also preserved in terms of flame geometry, flow residence time, turbulent kinetic energy, its dissipation, and turbulent mixing time and turbulent integral length scales (see Appendix A). This scaling is referred to as Froude modeling and is applied to design the high-pressure flames (see Table 1) based on the atmospheric pressure flame. It should be pointed out that the Froude modeling does not preserve the heat release rate (see Table 1), the soot production rate, and the Kolmogorov time scale (see Appendix A). 
Calculations were run for the three flames by considering the parameters given in Table 1 . The computational domain considers a nozzle centered in a $600-\mathrm{mm}-\mathrm{i} . \mathrm{d}$. blackened stainless steel chamber. The numerical calculations were performed in a computational domain of $0.3 \mathrm{~m}(\mathrm{r}) \times 1.2$ m (z) with $84(\mathrm{r}) \times 93(\mathrm{z})$ control volumes. The walls were assumed to behave as blackbody emitting at the computed surface temperature.

Figure 1 shows the contours of mixture fraction, temperature, and soot volume fraction in the three $\mathrm{CH}_{4}$ flames. The diagrams (a) to (c) compare these contours at $1 \mathrm{~atm}$ and 3 atm with the left-side and right-side of each diagram corresponding to the 1-atm and 3-atm flames, respectively. On the other hand, the diagrams (d) to (f) report a similar comparison between the 1-atm and 4-atm flames. Figures 1 (a) to (c) show that the mixture fraction and temperature contours are well preserved by the Froude modelling as the pressure is scaled up from 1 to 3 atm whereas, as expected, the soot volume fraction is significantly enhanced (see Appendix A). The peak soot volume fraction increases from $0.02 \mathrm{ppm}$ at 1 atm to $0.8 \mathrm{ppm}$ at $3 \mathrm{~atm}$ (see Fig. 1c). Figures 1 (d) to (f) show that these contours are also rather well preserved as the pressure is increased from $1 \mathrm{~atm}$ to $4 \mathrm{~atm}$. However, differences can be clearly observed. The radiative losses in the 4-atm $\mathrm{CH}_{4}$ flame are significantly higher than those in the 1-atm flame due to a strong increase in soot volume fraction from about $0.02 \mathrm{ppm}$ at 1 atm to about $4.3 \mathrm{ppm}$ at 4 atm. This induces modification in the temperature distribution (see Fig. 1e) which, explains the observed differences. The differences are more pronounced in temperature than in mixture fraction contours (see Figs. $1 \mathrm{~d}$ and e).

Table 2 quantifies the pressure effects on the flame geometry and flow residence time. The flame contour is defined by the isotherm of $1400 \mathrm{~K}$. This value is expected to correspond to a threshold below which soot ceases to be oxidized [33, 34], being then an indicator of the "luminous" flame contour. The mean flame height, flame volume, and flow residence time 
(Term I in Eq. 1) are $0.688 \mathrm{~m} \pm 0.003 \mathrm{~m}( \pm 0.5 \%), 3.2 \times 10^{-4} \mathrm{~m}^{3} \pm 1.4 \times 10^{-5} \mathrm{~m}^{3}( \pm 4.6 \%)$, and 490 $\mathrm{ms} \pm 22 \mathrm{~ms}( \pm 4.5 \%)$, respectively. These results indicate that the Froude modelling preserves the flame geometry and the flow residence time within 5\% as the pressure is increased from 1 to 4 atm.

Figure 2 shows the pressure effects on the axial profiles of axial velocity, turbulent kinetic energy, turbulent mixing time, and turbulent intensity based either on temperature $\left(\sqrt{\widetilde{T^{\prime 2}}} / \tilde{T}\right)$ or soot volume fraction $\left(\sqrt{\widetilde{f_{S}^{\prime 2}}} / \widetilde{f_{S}}\right)$. Arguments to explain the scaling observed for $\sqrt{\widetilde{f_{S}^{\prime 2}}} / \widetilde{f}_{S}$ are provided in Appendix B. It is clear from Fig. 2 that these quantities are also preserved by the Froude modelling. As a consequence, we can state that the Froude modelling preserves the flame and flow structures as the pressure is scaled up to 4 atm and allows to isolate the effects of pressure on soot production, RHT and TRI.

\subsection{Effects of pressure on radiant fraction}

Table 3 shows that the contribution of soot to total emission increases significantly as the pressure increases. Soot emission is negligible at 1 atm and contributes to about $15 \%$ and $33 \%$ of total emission at $3 \mathrm{~atm}$ and $4 \mathrm{~atm}$, respectively. Nevertheless, it should be pointed out that soot emission dominates locally in regions of high soot volume fractions in the 4-atm flame, where soot volume fraction reaches about $4 \mathrm{ppm}$.

On the other hand, the radiant fraction increases moderately with pressure, being enhanced by only $2 \%$ as the pressure rises from 1 atm to 3 atm and by about $20 \%$ as the pressure is further increased to 4 atm. 
This section aims to understand the pressure effects on the radiant fraction. As discussed previously, Term I in Eq. 2 is preserved by the Froude modelling and the effects of pressure on the radiant fraction are due to modifications to Terms II and III.

\subsubsection{Effects of pressure on Term II $\left(\dot{Q}_{e m}^{\prime \prime \prime} / \rho_{F} \Delta h_{c}\right)$}

The total emission per unit flame volume, $\dot{Q}_{e m}^{\prime \prime \prime}$, is the sum of the contributions of radiating gases, $\dot{Q}_{e m, G}^{\prime \prime \prime}$, and soot, $\dot{Q}_{e m, S}^{\prime \prime \prime}$. The emission of radiating gas per unit flame volume can be rewritten as:

$$
\dot{Q}_{e m, G}^{\prime \prime \prime}=\frac{1}{V_{f l}} \int_{V_{f l}}\left\langle\kappa_{p, G} I_{b}\right\rangle d V \propto P
$$

$\dot{Q}_{e m, G}^{\prime \prime \prime}$ is expected to increase linearly with $P$ since, on one hand, the Planck-mean absorption coefficient of radiating gases scales with $P[35]$ and, on the other hand, the temperature, species mole fractions, and turbulent intensity are on the whole preserved by the Froude modelling. Moreover, $\rho_{F} \propto P$ and consequently, the term $\dot{Q}_{e m, G}^{\prime \prime \prime} / \rho_{F} \Delta h_{c}$ is expected to be independent of $P$. This behavior is illustrated in the second column of Table 4 and in Fig. 3a where $\dot{Q}_{e m, G}^{\prime \prime \prime} / \rho_{F} \Delta h_{c}$ is observed to remain constant as $P$ increases from 1 to 3 atm and to increase by about $8 \%$ as the pressure increases to $4 \mathrm{~atm}$. The flame structure is not fully-preserved by the Froude modeling as the pressure increases to $4 \mathrm{~atm}$, explaining these small variations.

In an opposite way, Fig. 3a shows that $\dot{Q}_{e m, S}^{\prime \prime \prime} / \rho_{F} \Delta h_{c}$ increases dramatically with $P$. The rates of increase are quantified in the third column of Table 4 . Term II, $\dot{Q}_{e m, S}^{\prime \prime \prime} / \rho_{F} \Delta h_{c}$, increases by a factor of about 14 as the pressure is raised from 1 to 3 atm and by about a factor of 40 as the pressure is increased to $4 \mathrm{~atm}$. Figure $3 \mathrm{~b}$ indicates that $\dot{Q}_{e m, S}^{\prime \prime \prime} / \rho_{F} \Delta h_{c}$ increases linearly with the equivalent soot volume fraction, $f_{S, E Q}$, defined as: 
$f_{S, E Q}=\frac{\max _{z}\left(2 \pi \int f_{S} r d r\right)}{\pi W_{f l}^{2}}$

where $W_{f l}$ is the flame width, showing that the enhanced soot production by $P$ is directly responsible for the increase in $\dot{Q}_{e m, S}^{\prime \prime \prime} / \rho_{F} \Delta h_{c}$.

The last column of Table 4 quantifies the increase in $\dot{Q}_{e m}^{\prime \prime \prime} / \rho_{F} \Delta h_{c}$ with $P$. As expected, its rate of increase is significantly slower than that of $\dot{Q}_{e m, S}^{\prime \prime \prime} / \rho_{F} \Delta h_{c}$ since the total gas emission dominates in the present flames.

\subsubsection{Effects of pressure on flame transparency}

The ratio of total absorption, $\dot{Q}_{a b s}$, to total emission, $\dot{Q}_{e m}$, is a measure of the flame selfabsorption. The second column of Table 5 indicates that, as expected, $\dot{Q}_{a b s} / \dot{Q}_{e m}$ is enhanced as the pressure raises, indicating that the rate of increase in $\dot{Q}_{a b s}$ with increasing $P$ is higher than that of $\dot{Q}_{e m}$. As a consequence, the flame transparency (Term III in Eq. 1) is reduced by pressure rise (see the third column of Table 5). The fourth and fifth columns in Table 5 quantify the contributions of soot and radiating gases to the flame self-absorption, respectively. It appears clearly that both contributions tend to enhance the flame self-absorption as the pressure increases and the rate of increase in the soot contribution is significantly higher owing to the strong increase in soot production. The last three columns of Table 5 show the contribution of radiating gases and soot to the total absorption and total emission. It can be observed that soot is comparatively more transparent than the radiating gases. This conclusion is consistent with that reported in Refs. [24, 36].

\subsection{Effects of pressure on TRI}


TRI affects the radiative loss mainly through the emission TRI. The gas and soot emission TRI terms can be developed as [10]:

$$
\begin{gathered}
\left\langle\kappa_{p} I_{b}\right\rangle \approx \underbrace{\kappa_{p}\left(\langle\phi\rangle I_{b}(\langle T\rangle)\right.}_{\left\langle\kappa_{p} I_{b}\right\rangle_{\text {NOTRI }}}+\underbrace{\left[\left\langle\kappa_{p}\right\rangle-\kappa_{p}(\langle\phi\rangle)\right] I_{b}(\langle T\rangle)}_{A}+\underbrace{\left\langle\kappa_{p}\right\rangle\left(\frac{\partial^{2} I_{b}}{\partial T^{2}}\right)_{\langle T\rangle} \frac{\left\langle T^{\prime 2}\right\rangle}{2}}_{B} \\
+\underbrace{\left(\frac{\partial I_{b}}{\partial T}\right)_{\langle T\rangle}\left\langle\kappa_{p}^{\prime} T^{\prime}\right\rangle}_{C}
\end{gathered}
$$

TRI contributes to emission through the last three terms in Eq. (7). Terms A, B and C represent the effects of the Planck-mean absorption coefficient self-correlation, the effects of the temperature self-correlation, and the effects of the cross-correlation between the Planck-mean absorption coefficient and temperature, respectively.

In the case of radiating gases, the three contributions tend to enhance emission [37]. This is illustrated in Table 6 where considering TRI enhances gas emission. Table 6 shows also that this enhancement increases with increasing the pressure which is in accordance with the conclusions drawn previously in Ref. [15] for non-luminous flames.

In the case of soot, terms $\mathrm{A}$ and $\mathrm{C}$ evolve as the cross-correlation between temperature and soot volume fraction which was observed to be negative in the region of strong soot emission in both experimental [38-41] and numerical [17, 36, 42, 43] investigations of turbulent diffusion flames. This negative behavior is illustrated in Fig. 4 for the present flames. As a consequence, these two terms tend to reduce soot emission [17, 36, 43]. On the other hand, term B is always positive and tends to enhance soot emission. Table 7 shows that taking TRI into account slightly reduces the total soot emission, indicating that, for the present flames, terms $\mathrm{A}$ and $\mathrm{C}$ prevail over term B. Term B is expected to increase with pressure due to an increase in soot volume fraction and consequently in $\left\langle\kappa_{p}\right\rangle$. On the other hand, terms $\mathrm{A}$ and $\mathrm{C}$ behave as $\overline{f_{S}^{\prime} T^{\prime}}=$ 
$C_{f_{S} T} \sqrt{\widetilde{f_{S}^{\prime 2}}} \sqrt{\widetilde{T^{\prime 2}}}$. Figure 4 shows that, in the region of soot emission, $C_{f_{S} T}$ reaches similar levels for all the flames and, as a consequence, terms $\mathrm{A}$ and $\mathrm{C}$ are expected to become more and more negative as the pressure is enhanced owing to an increase in the fluctuation of the soot volume fraction $\left(\sqrt{\widetilde{f_{S}^{\prime 2}}}\right)$. Table 7 shows that the reduction in soot emission TRI decreases slightly as the pressure increases. This suggests that term B increases with $P$ at a slightly higher rate than that of the decrease of terms A and B.

As a consequence, TRI affects the total emission through a competition between the enhancement mechanisms, i.e., gas emission TRI and the effects of the temperature selfcorrelation on soot emission, and reducing mechanisms, i.e., the effects of terms $\mathrm{A}$ and $\mathrm{C}$ on soot emission. Soot emission plays an unimportant role in the 1-atm flame and then TRI increases significantly the total emission and consequently the net radiative loss (see Table 8). As the pressure increases, the contribution of soot becomes higher. However, the enhancement in the total emission and net radiative loss is limited due to the inhibiting effects of terms A and B on soot emission (see Table 8).

Let us consider the local effects of TRI on the radial profiles of the divergence of radiative flux. These effects are illustrated in Figs. 5 and 6 for the 1-atm and 4-atm flames, respectively. In each figure, the radial profiles are displayed at three heights of $0.2 \mathrm{~m}, 0.4 \mathrm{~m}$, and $0.6 \mathrm{~m}$ corresponding respectively to the lower part of the flame where soot growth dominates, the middle of the flame where the maximum soot volume fraction is encountered, and the upper part of the flame where soot is intensely oxidized (see Fig. 1). Soot radiation is negligible in the 1-atm flame and taking TRI into account enhances gas emission and, correspondingly, the divergence of radiative flux (see Fig. 5). In addition, the TRI effects are pronounced in regions where temperature fluctuations are high, i.e., near the flame wings at $z=0.2 \mathrm{~m}$ and $0.4 \mathrm{~m}$ and 
over the entire flame width in the upper part of the flame $(z=0.6 \mathrm{~m})$. For the 4-atm flame, soot radiation becomes significant. Figure 6 shows that, in the regions where soot volume fractions are high, TRI tends to reduce the divergence of radiative flux. This means that in these regions the terms that tend to reduce emission, i.e., terms $\mathrm{A}$ and $\mathrm{B}$ in the soot emission term, dominate those that tend enhance it, i.e., the gas emission TRI and the temperature self-correlation effects on soot emission TRI. Conversely, Fig. 6 shows that, in regions where soot volume fractions are low considering TRI enhances the divergence of radiative flux. In these regions gas radiation is dominant and, as a consequence, the TRI mechanisms that tend to enhance emission and the divergence of radiative flux prevail over those that tend to suppress them.

\section{Conclusions}

The effects of pressure on radiative heat transfer and turbulence radiation interaction were investigated in $\mathrm{CH}_{4}$ turbulent jet diffusion flames at pressures up to 4 atm by using a wellvalidated numerical model. The following conclusions can be drawn from the results of the present study.

1) The Froude modelling preserves the flame structure in terms of flame geometry, global residence time, turbulent kinetic energy, its dissipation, turbulent mixing times, turbulent integral length scale, and turbulent fluctuations up to 4 atm. However, it becomes less accurate as the pressure further increases due to the strong increase in soot production.

2) The radiant fraction is determined by three mechanisms: I) a global residence time preserved by the Froude modeling, II) the inverse of an emission characteristic time scale, and III) a term characterizing the flame transparency that is reduced as the pressure increases. The contribution of gas emission to Mechanism II is independent of the pressure whereas the soot contribution increases significantly with pressure owing to strong enhancement in soot production. The 
radiant fraction in sooting flames evolves with pressure owing to a competition between Mechanisms II and III. For the present flames, the second mechanism (II) was found to dominate over the third (III), leading to an increase in the radiant fraction with increasing pressure.

3) The effects of TRI on radiative loss are governed by a competition between mechanisms that tend to enhance emission, i.e., gas emission TRI and temperature self-correlation effects on soot emission, and those that tend to reduce it, i.e., the negative correlation between the soot volume fraction and temperature that reduces soot emission. The former mechanisms dominate in the weakly sooting 1-atm flame. The latter mechanisms become increasingly important as the pressure increases which limits the increase in the global radiative loss due to TRI. In addition, model results show that, for the high-pressure flames, the TRI effects can reduce the local radiative loss in the high soot concentration regions of the flame.

\section{References}

[1]. Modest MF, Haworth DC. Radiative Heat Transfer in Turbulent Combustion Systems: Theory and Applications. Springer: New-York; 2016.

[2].Pal G, Modest MF. k-Distribution methods for radiation calculations in high-pressure combustion, J. Thermophys. Heat Transf. 2013; 27: 584-7.

[3]. Pearson JT, Webb BW, Solovjov VP, Ma J. Efficient representation of the absorption line blackbody distribution function for $\mathrm{H}_{2} \mathrm{O}, \mathrm{CO}_{2}$ and $\mathrm{CO}$ at variable temperature, mole fraction, and total pressure. J. Quant. Spectrosc. Radiat. Transf. 2014; 138: 82-96.

[4]. Chu H, Gu M, Consalvi JL, Liu F, Zhou H. Effects of total pressure on non-grey gas radiation transfer in oxy-fuel combustion using the LBL, SNB, SNBCK, WSGG, and FSCK methods. J. Quant. Spectrosc. Radiat. Transf. 2016; 172: 24-35. 
[5]. Modest MF, Riazzi RJ. Assembly full spectrum $k$-distribution from a narrow band database: effects of mixing gases, gases and non-gray absorpting particles and non-gray scatters in non-gray enclosures. J. Quant. Spectrosc. Radiat. Trans. 2005; 90: 169-89.

[6]. Chu H, Consalvi JL, Gu M, Liu F. Calculations of radiative heat transfer in an axisymmetric jet diffusion flame at elevated pressures using different gas radiation models. J. Quant. Spectrosc. Radiat. Transf. 2017; 197: 12-25.

[7]. McCrain LL, Roberts WL. Measurements of the soot volume field in laminar diffusion flames at elevated pressures. Combust. Flame 2005; 140: 60-9.

[8].Karataş AE, Gülder ÖL. Soot formation in high pressure laminar diffusion flames, Prog. Ener. Combust. Sci. 2012; 38: 818-45.

[9].Gülder ÖL, Intasopa G, Joo HI, Mandatori PM, Bento DS, Vaillancourt ME. Unified behaviour of maximum soot yields of methane, ethane and propane laminar diffusion flames at high pressures. Combust. Flame 2011; 158: 2037-44.

[10]. Coelho PJ. Numerical simulation of the interaction between turbulence and radiation in reactive flows. Prog. Energy Combust. Sci. 2007; 33: 311-383.

[11]. Coelho PJ. Turbulence-Radiation Interaction: From Theory to Application in Numerical Simulations. J. Heat Transfer 2012; 134: 031001.

[12]. Cai J, Lei S, Dasgupta A, Modest MF, Haworth DC. High fidelity radiative heat transfer models for high-pressure laminar hydrogen-air diffusion flames. Combust. Theor. Model. 2014; 18: 606-27.

[13]. Ferreyro Fernandez S, Paul C, Sircar A, Imren A, Haworth DC, Roy S, Modest MF. Soot and spectral radiation modeling for high-pressure turbulent spray flames. Combust. Flame 2018; 190: 402-15. 
[14]. Paul C, Haworth DC, Modest MF, A simplified CFD model for spectral radiative heat transfer in high-pressure hydrocarbon-air combustion systems, Proc. Combust. Inst. 2019; 37: 4617-24.

[15]. Nmira F, Consalvi JL, André F. Pressure effects on radiative heat transfer in hydrogen/air turbulent diffusion flames. J. Quant. Spectrosc. Radiat. Transf. 2018; 220: $172-9$.

[16]. Consalvi JL, Nmira F, Burot D. Simulations of sooting turbulent jet flames using a hybrid flamelet/stochastic Eulerian field method. Combust. Theor. Model. 2016; 20: 221-57.

[17]. Consalvi JL, Nmira F. Effects of soot absorption coefficient-Planck function correlation on radiative heat transfer in oxygen-enriched propane turbulent diffusion flame. J. Quant. Spectrosc. Radiat. Transf. 2016; 172: 50-7.

[18]. Consalvi JL, Nmira F. Transported scalar PDF modeling of oxygen-enriched turbulent jet diffusion flames: Soot production and radiative heat transfer. Fuel 2016; 178: 37-48.

[19]. Qin Z, Lissianski VV, Yang H, Gardiner WC, Scott SG, Wang H. Combustion chemistry of propane: a case study of detailed reaction mechanism optimization. Proc. Combust .Inst. 2000; 28: 1663-9.

[20]. Lindstedt RP. Simplified soot nucleation and surface growth steps for non-premixed flames. In: Bockhorn H, editor. Soot formation in combustion: mechanism and models. Berlin: Springer-Verlag; 1994.

[21]. Leonard B.P., Drummond J.E. Why you should not use hybrid, power-law or related exponential schemes for convective modelling. There are much better alternatives. Int. J. Numer. Method Fluids 1995; 20: 421-442.

[22]. Chow W.K., Cheung Y. L. Selection of differencing scheme on simulating the sprinkler hot-air layer problem. Numer. Heat Trans. - Part A 1999; 35: 311-330. 
[23]. Valiño L. A field Monte Carlo formulation for calculating the probability density function of a single scalar in a turbulent flow. Flow. Turbul. Combust. 1998; 29: 2139-46.

[24]. Mehta RS, Modest MF, Haworth DC. Radiation characteristics and turbulence-radiation interactions in sooting turbulent jet flames. Combust. Theory Model. 2010; 14: 105-24.

[25]. Consalvi JL, Nmira F. Absorption turbulence-radiation interactions in sooting turbulent jet flames. J. Quant. Spectrosc. Radiat. Transf. 2017; 201: 1-9.

[26]. Chang H, Charalampopoulos T. Determination of the wavelength dependence of refractive indices of flame soot. Proc. R Soc. 1990; 430: 577-91.

[27]. Pearson JT, Webb BW, Solovjov VP, Ma J. Updated correlation of the absorption line blackbody distribution function for H2O based on the HITEMP2010 database. J. Quant. Spectrosc. Radiat. Transf. 2013; 128: 10-17.

[28]. Chui EH, Raithby GD, Hughes PMJ. Prediction of radiative transfer in cylindrical enclosures with the finite volume method. J. Thermophys. Heat Trans. 1992; 6: 605-611.

[29]. Brookes SJ, Moss JB. Measurements of soot production and thermal radiation from confined turbulent jet diffusion flames of methane. Combust. Flame 1999; 116: 49-61.

[30]. Consalvi JL, Nmira F. Modeling of large-scale under-expanded hydrogen jet fires. Proc. Combust. Inst. 2019; 37: 3943-50.

[31]. Turns SR, Myhr FH. Oxides of nitrogen emissions from turbulent jet flames: Part I-Fuel effects and flame radiation. Combust. Flame 1991; 87: 319-35.

[32]. Delichatsios MA. Transition from momentum to buoyancy-controlled turbulent jet diffusion flames and flame height relationships. Combust. Flame 1993; 92: 349-64.

[33]. Markstein GH, De Ris J. Radiant emission and absorption by laminar ethylene and propylene diffusion flames. Proc. Combust. Inst. 1985; 20: 1637-46.

[34]. Kent JH. A quantitative relationship between soot yield and smoke point measurements. Combust. Flame 1986; 63: 349-58. 
[35]. Modest MF. Radiative Heat Transfer. Academic Press. 2003.

[36]. Rodrigues P, Gicquel O, Franzelli B, Darabiha N, Vicquelin R, Analysis of radiative transfer in a turbulent sooting jet flame using a Monte Carlo method coupled to large eddy simulation, J. Quant. Spectrosc. Radiat. Transf. 2019; 235: 187-203.

[37]. Li G, Modest MF. Importance of turbulence-radiation interactions in turbulent diffusion je flames. J. Heat Transf. 2003; 125: 831-8.

[38]. Sivathanu YR, Gore JP, Dolinear J. Transient scalar properties of strongly radiating jet flames, Combust. Sci. and Tech. 1991; 76: 45-66.

[39]. Sivathanu YR, Gore JP. Transient structure and radiation properties of strongly radiating buoyant flames. J. Heat Transf. 1992; 114: 659-65.

[40]. Murphy JJ, Shaddix CR. Soot properties and species measurements in a two-meter diameter JP-8 pool fire. Sandia Report, SAND20034246, 2003.

[41]. Zeng D, Chatterjee P, Wang Y. The effect of oxygen depletion on soot and thermal radiation in buoyant turbulent diffusion flames, Proc. Combust. Inst. 2019; 37: 825-32.

[42]. Kollmann W, Kennedy IM, Metternich M, Chen JY. Application of a soot model to a turbulent ethylene diffusion flame. in: Bockhorn H (Eds.). Soot Formation in Combustion: Mechanism and Models. Springer-Verlag, Berlin, 1994, pp. 503-526.

[43]. Nmira F, Burot D., Consalvi J.L. Soot emission radiation-turbulence interactions in diffusion jet flames, Combust. Sci. Technol. 2019; 191: 126-36.

[44]. De Ris JL, Wu PK, Heskestad G. Fire radiation modelling. Proc. Combust. Inst. 28; 2000: 2751-9.

[45]. Mueller ME, Pitsch H. Large eddy simulation subfilter modeling of soot-turbulence interactions. Physics of Fluid 23 (2011) 115104. 


\section{Appendix A. Froude modeling}

This appendix discusses how the flow properties evolve with pressure in Froude modelling. The analysis is based on the assumption that the flames considered in the present study are in the momentum-driven regime. This simplifies the analysis since the characteristic flow length, $L_{C}$, and velocity, $U_{C}$, scales are the nozzle diameter (see Eq. 2) and the fuel injection velocity, $u_{F}$ :

$$
\begin{aligned}
& L_{C} \propto L_{f l} \propto d_{F} \\
& U_{C} \propto u_{f l} \propto u_{F}
\end{aligned}
$$

The Froude modeling preserves these two quantities as the pressure is scaled up. The characteristic flow time scale is then also independent of pressure:

$$
t_{C}=L_{C} / U_{c} \propto d_{F} / \mathrm{u}_{F} \propto P^{0}
$$

The turbulent kinetic energy, dissipation of turbulent kinetic energy, turbulent mixing time and integral length scale are also independent of pressure:

$$
\begin{aligned}
& \mathrm{k} \propto U_{C}^{2} \propto u_{F}^{2} \propto P^{0} \\
& \varepsilon \propto U_{C}^{3} / L_{c} \propto u_{F}^{3} / d_{F} \propto P^{0} \\
& t_{m i x} \propto \mathrm{k} / \varepsilon \propto P^{0} \\
& l_{e} \propto \mathrm{k}^{3 / 2} / \varepsilon \propto P^{0}
\end{aligned}
$$

The flame width can be estimated by assuming that the time scale for fuel convection in the axial direction is of the same order of magnitude as the turbulent diffusion time scale of fuel in the radial direction: 
$\frac{\mathrm{L}_{f l}}{u_{F}} \propto \frac{W_{f l}^{2}}{k^{2} / \varepsilon}$

Equations A1, A2, A4 and A5 show that $W_{f l}$ is preserved by the Froude modelling. As a consequence, the flame volume, $V_{f l} \propto L_{f l} W_{f l}^{2}$, and the flow residence time (Term I in Eq. 1), $t_{r e s} \propto V_{f l} / u_{F} d_{F}^{2}$ scale with $P^{0}$

The maximum soot volume fraction scales as [44]:

$f_{S, \max } \propto \rho_{f l} Y_{S, \max } \propto \dot{\omega}_{S F}^{\prime \prime \prime} t_{S}$

where $t_{S}$ and $\dot{\omega}_{S F}^{\prime \prime \prime}$ are the flow time for soot production and the soot formation rate, respectively. In turbulent flames, several studies suggested that the Kolmogorov microscale time, $t_{K o l}=$ $\sqrt{\mu_{f l} L_{f l} / \rho_{f l} u_{F}^{3}} \propto P^{-1 / 2}$ is the flow time for soot formation [42]. On the other hand, soot formation and oxidation rates are enhanced as $P$ increases, leading to $\dot{\omega}_{S F}^{\prime \prime \prime} \propto P^{n}$ with $\mathrm{n}>0$ and ranging typically from 1 to 3 [8]. As a consequence, $f_{S, \max } \propto P^{n-1 / 2}$ and soot production is not preserved by the Froude modelling.

\section{Appendix B.}

Due to flame intermittency, the PDF of soot volume fraction is expected to behave as a double$\delta$ distribution with a "nonsooting" mode and a "sooting" mode [45][45]:

$$
\tilde{P}\left(f_{S}\right)=\omega \delta\left(f_{S}\right)+(1-\omega) \delta\left(f_{S}-f_{S}^{*}\right)
$$

where $\omega$ is the soot intermittency and $f_{S}^{*}$ is the soot volume fraction in the sooting mode.

$f_{S}^{*}$ can be related to the mean soot volume fraction and the soot intermittency as: 


$$
\widetilde{f}_{S}=\int f_{S} \tilde{P}\left(f_{S}\right) d f_{S}=(1-\omega) f_{S}^{*}
$$

On the other hand, the flame intermittency is related to $\widetilde{f_{S}^{2}}$ through:

$$
\widetilde{f_{S}^{2}}=\int f_{S}^{2} \widetilde{P}\left(f_{S}\right) d f_{S}=(1-\omega) f_{S}^{* 2}=\widetilde{f}_{S}^{2} /(1-\omega)
$$

From Eq. (B3), $\omega$ and $A=\sqrt{\widetilde{f_{S}^{\prime \prime 2}}} / \widetilde{f}_{S}$ are closely related through $\omega=\frac{A^{2}}{1+A^{2}}$. The Froude modelling is expected to preserve the turbulent flame structure and, as a result, the flame intermittency. This may explains the self-similarity of $\sqrt{\widetilde{f_{S}^{\prime \prime 2}}} / \widetilde{f}_{S}$ observed in Fig. 2d. 
Table 1. Fuel injection parameters.

\begin{tabular}{|c|c|c|c|c|}
\hline Pressure (atm) & $U_{F}(\mathrm{~m} / \mathrm{s})$ & $d_{F}(\mathrm{~mm})$ & $\operatorname{Fr}(-)$ & $\dot{Q}_{c}(\mathrm{~kW})$ \\
\hline 1 & 133 & 2.5 & 5 & 21.3 \\
\hline 3 & - & - & - & 63.9 \\
\hline 4 & - & - & - & 85.2 \\
\hline
\end{tabular}

Table 2. Froude modelling: conservation of flame geometry and flow residence time.

\begin{tabular}{|c|c|c|c|}
\hline$P(\mathrm{~atm})$ & $\begin{array}{c}L_{f l}(\mathrm{~m}) \\
\mathrm{T}=1400 \mathrm{~K}\end{array}$ & $\begin{array}{c}V_{f l}\left(\mathrm{~m}^{3}\right) \\
\mathrm{T}=1400 \mathrm{~K}\end{array}$ & $\begin{array}{c}t_{\text {res }}(\mathrm{ms}) \\
\mathrm{T}=1400 \mathrm{~K}\end{array}$ \\
\hline 1 & 0.687 & $3.09 \times 10^{-4}$ & 474 \\
\hline 3 & 0.693 & $3.37 \times 10^{-4}$ & 516 \\
\hline 4 & 0.686 & $3.14 \times 10^{-4}$ & 481 \\
\hline
\end{tabular}

Table 3. Effect of pressure on the contribution of soot to emission and radiant fraction.

\begin{tabular}{|c|c|c|}
\hline$P(\mathrm{~atm})$ & $\dot{Q}_{e m, S}^{\prime \prime \prime} / \dot{Q}_{e m}^{\prime \prime \prime}$ & $\chi_{R}(-)\left(\chi_{R, P} / \chi_{R, P=1}\right)$ \\
\hline 1 & 0.012 & $0,162(1.00)$ \\
\hline 3 & 0.14 & $0,165(1.02)$ \\
\hline 4 & 0.33 & $0,192(1.20)$ \\
\hline
\end{tabular}


Table 4. Effect of pressure on gas and soot emission.

\begin{tabular}{|c|c|c|c|}
\hline$P(\mathrm{~atm})$ & $\begin{array}{c}C_{g a s}=\dot{Q}_{e m, G}^{\prime \prime \prime} / \rho_{F} \Delta h_{c}\left(\mathrm{~s}^{-1}\right) \\
\left(C_{g a s, P} / C_{g a s, P=1}\right)\end{array}$ & $\begin{array}{c}C_{\text {soot }}=\dot{Q}_{e m, S}^{\prime \prime \prime} / \rho_{F} \Delta h_{c}\left(\mathrm{~s}^{-1}\right) \\
\left(C_{\text {soot }, P} / C_{\text {soot }, P=1}\right)\end{array}$ & $\begin{array}{c}\text { Term II } \\
\left(\mathrm{II}_{, \mathrm{P}} / I_{, P=1}\right)\end{array}$ \\
\hline 1 & $0.524(1.00)$ & $0.006(1.00)$ & $0.53(1.00)$ \\
\hline 3 & $0.524(1.00)$ & $0.085(13.90)$ & $0.61(1.15)$ \\
\hline 4 & $0.566(1.08)$ & $0.24(40.40)$ & $0.82(1.53)$ \\
\hline
\end{tabular}

Table 5. Effect of pressure on flame optical thickness and flame transparency.

\begin{tabular}{|c|c|c|c|c|c|}
\hline$P(\mathrm{~atm})$ & $\begin{array}{c}\tau=\dot{Q}_{a b s}^{\prime \prime \prime} / \dot{Q}_{e m}^{\prime \prime \prime} \\
\left(\tau_{, \mathrm{P}} / \tau_{, P=1}\right)\end{array}$ & $\begin{array}{c}\text { Term III } \\
\left(\mathrm{III}, \mathrm{P} / I I I_{, P=1}\right)\end{array}$ & $\dot{Q}_{a b s, G}^{\prime \prime \prime} / \dot{Q}_{\text {em }}^{\prime \prime \prime}$ & $\dot{Q}_{a b s, S}^{\prime \prime \prime} / \dot{Q}_{e m}^{\prime \prime \prime}$ & $\dot{Q}_{\text {em },}^{\prime \prime \prime} / \dot{Q}_{e m}^{\prime \prime \prime}$ \\
\hline 1 & $0.356(1.00)$ & $0.644(1.00)$ & 0.355 & 0 & 0.012 \\
\hline 3 & $0.475(1.34)$ & $0.525(0.814)$ & 0.461 & 0.013 & 0.14 \\
\hline 4 & $0.502(1.41)$ & $0.498(0.773)$ & 0.428 & 0.072 & 0.33 \\
\hline
\end{tabular}

Table 6. Effect of pressure on gas emission TRI.

\begin{tabular}{|c|c|c|c|}
\hline$P(\mathrm{~atm})$ & $\begin{array}{c}\left(\dot{Q}_{e m, G}\right)_{T R I} \\
(\mathrm{~kW})\end{array}$ & $\begin{array}{c}\left(\dot{Q}_{\text {em }, G}\right)_{\text {NoTRI }} \\
(\mathrm{kW})\end{array}$ & $\begin{array}{c}\Delta T R I \\
(\%)\end{array}$ \\
\hline 1 & 5.29 & 4.12 & 22.00 \\
\hline 3 & 17.20 & 13.4 & 22.20 \\
\hline 4 & 23.10 & 16.6 & 28.84 \\
\hline
\end{tabular}


Table 7. Effect of pressure on soot emission TRI.

\begin{tabular}{|c|c|c|c|}
\hline$P(\mathrm{~atm})$ & $\begin{array}{c}\left(\dot{Q}_{\text {em }, S}\right)_{T R I} \\
(\mathrm{~kW})\end{array}$ & $\begin{array}{c}\left(\dot{Q}_{\text {em }, S}\right)_{\text {NoTRI }} \\
(\mathrm{kW})\end{array}$ & $\begin{array}{c}\Delta T R I \\
(\%)\end{array}$ \\
\hline 1 & 0.082 & 0,086 & -4.51 \\
\hline 3 & 2.81 & 2.88 & -2.57 \\
\hline 4 & 10.1 & 10.2 & -0.99 \\
\hline
\end{tabular}

Table 8. Effect of pressure and TRI on the net radiative loss, $\dot{Q}_{n e t}=\dot{Q}_{e m}-\dot{Q}_{a b s}$.

\begin{tabular}{|c|c|c|c|}
\hline$P(\mathrm{~atm})$ & $\begin{array}{c}\left(\dot{Q}_{\text {net }}\right)_{T R I} \\
(\mathrm{~kW})\end{array}$ & $\begin{array}{c}\left(\dot{Q}_{\text {net }}\right)_{\text {NoTRI }} \\
(\mathrm{kW})\end{array}$ & $\begin{array}{c}\Delta T R I \\
(\%)\end{array}$ \\
\hline 1 & 3.45 & 2.61 & 24,10 \\
\hline 3 & 10.50 & 8.45 & 19.50 \\
\hline 4 & 16.60 & 13.5 & 18.20 \\
\hline
\end{tabular}




\section{LIST OF FIGURE CAPTIONS}

Figure 1. Fields of mixture fraction (a or d), temperature (b or d) and soot volume fraction (c or f) at 1 and 3 atm (left row) and 1 and 4 atm (right row).

Figure 2. Fields of mixture fraction (a or d), temperature (b or d) and soot volume fraction (c or f) at 1 and 3 atm (left row) and 1 and 4 atm (right row).

Figure 3. a) Evolution of $\dot{Q}_{e m}^{\prime \prime \prime} / \rho_{F} \Delta h_{c}$ as a function of pressure and b) $\dot{Q}_{e m, S}^{\prime \prime \prime}$ as a function of the equivalent soot volume fraction defined as: $f_{S, E Q}=\max _{z}\left(2 \pi \int r f_{s} d r\right) / \pi W_{f l}^{2}$.

Figure 4. Fields of the correlation between soot volume fraction and temperature and of soot volume fraction for the flames at a) $1 \mathrm{~atm}$, b) $3 \mathrm{~atm}$, and c) $4 \mathrm{~atm}$. For each diagram the right row corresponds to the correlation between soot volume fraction and temperature and the left row to the soot volume fraction.

Figure 5. Effects of pressure on the radial profiles of the divergence of radiative flux for the 1 atm flame at a) $\mathrm{z}=0.2 \mathrm{~m}, \mathrm{~b}) \mathrm{z}=0.4 \mathrm{~m}$, and c) $\mathrm{z}=0.6 \mathrm{~m}$.

Figure 6. Effects of pressure on the radial profiles of the divergence of radiative flux for the 4 atm flame at a) $\mathrm{z}=0.2 \mathrm{~m}, \mathrm{~b}) \mathrm{z}=0.4 \mathrm{~m}$, and c) $\mathrm{z}=0.6 \mathrm{~m}$. 

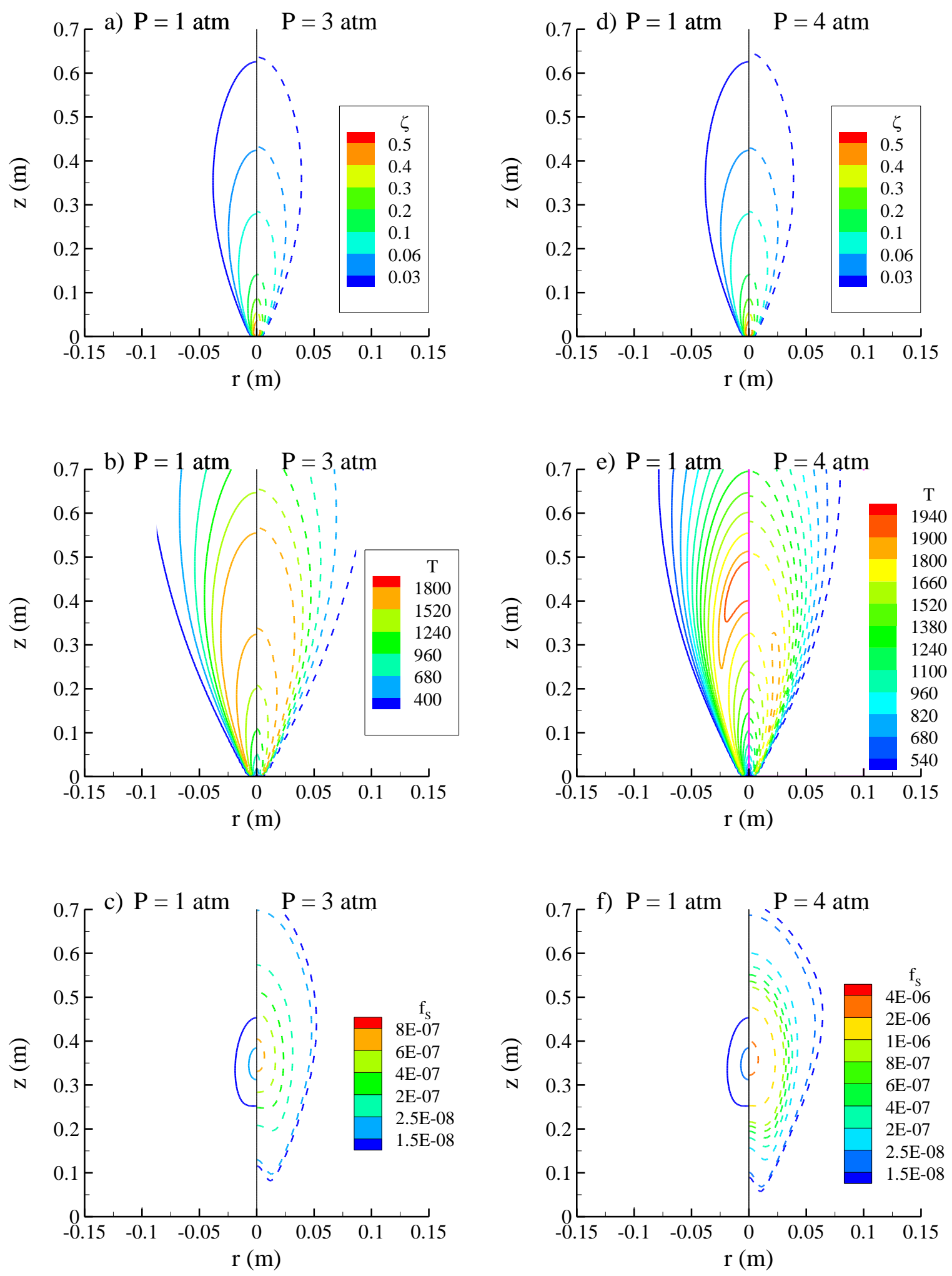

Figure 1. Effect of pressure on the fields of mixture fraction (a or d), temperature (b or d) and soot volume fraction (c or f) at 1 and 3 atm (left row) and 1 and 4 atm (right row). 

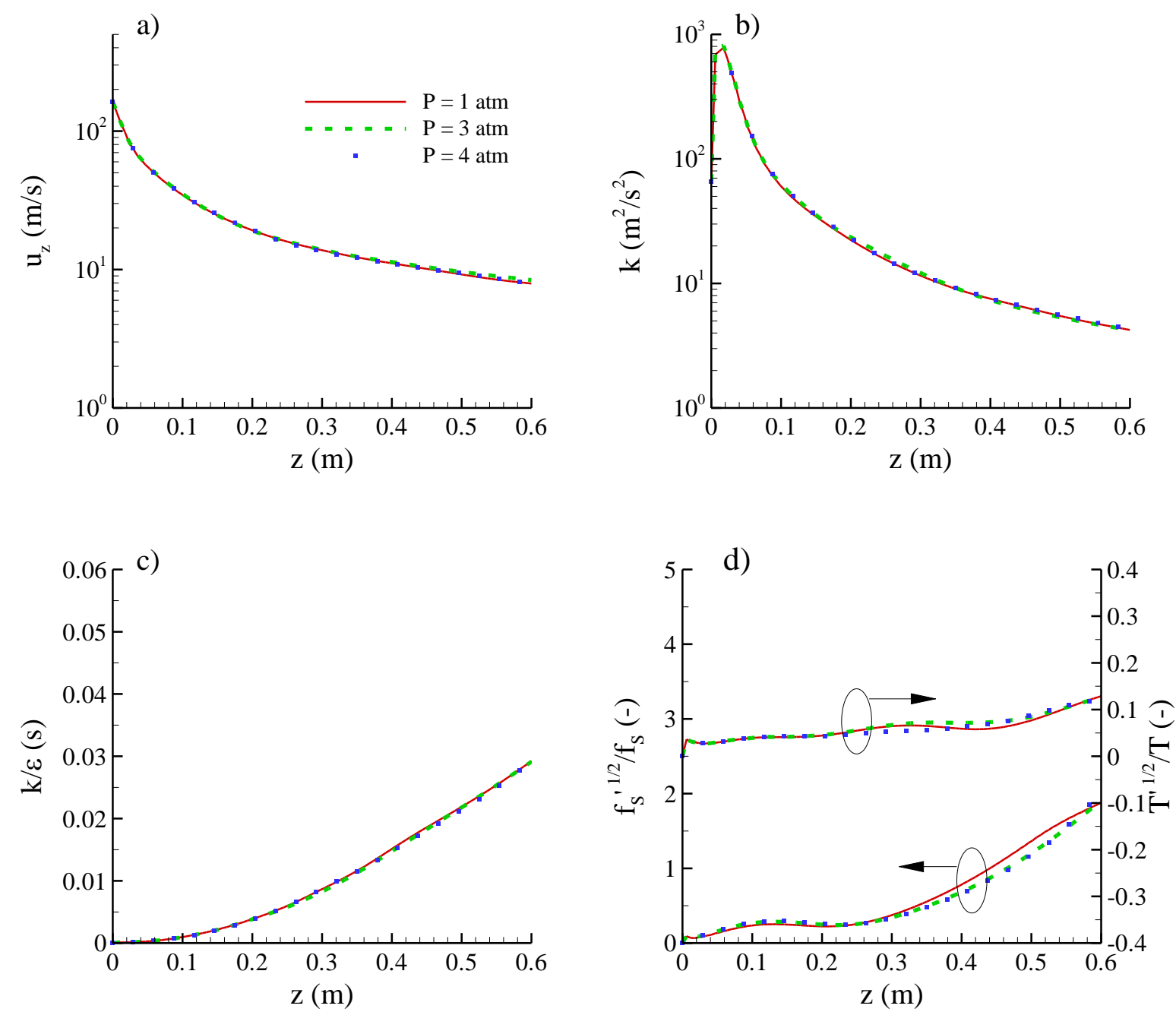

Figure 2. Effects of pressure on the axial evolution of the axial velocity (a), turbulent kinetic energy (b), turbulent mixing time (c) and axial turbulent intensity (d). 

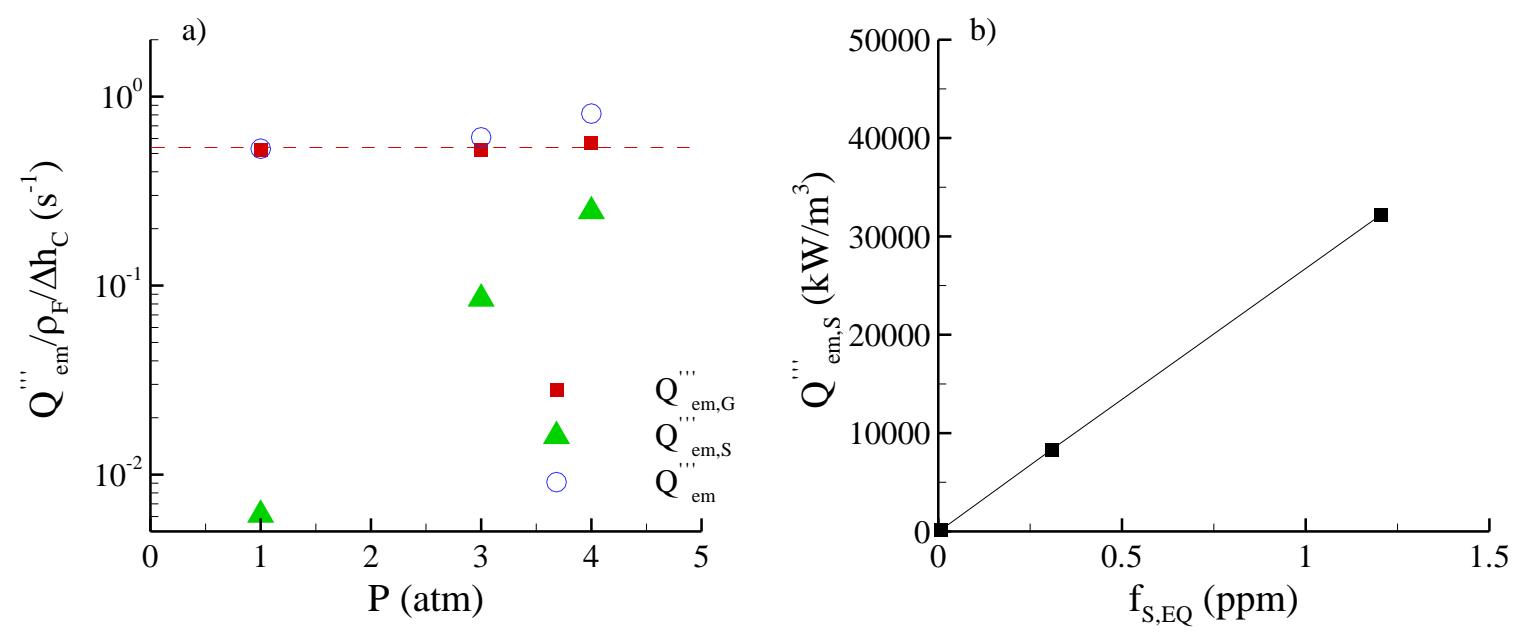

Figure 3. a) Evolution of $\dot{Q}_{e m}^{\prime \prime \prime} / \rho_{F} \Delta h_{c}$ as a function of pressure and b) $\dot{Q}_{e m, S}^{\prime \prime \prime}$ as a function of the equivalent soot volume fraction defined as: $f_{S, E Q}=\max _{z}\left(2 \pi \int r f_{s} d r\right) / \pi W_{f l}^{2}$. 

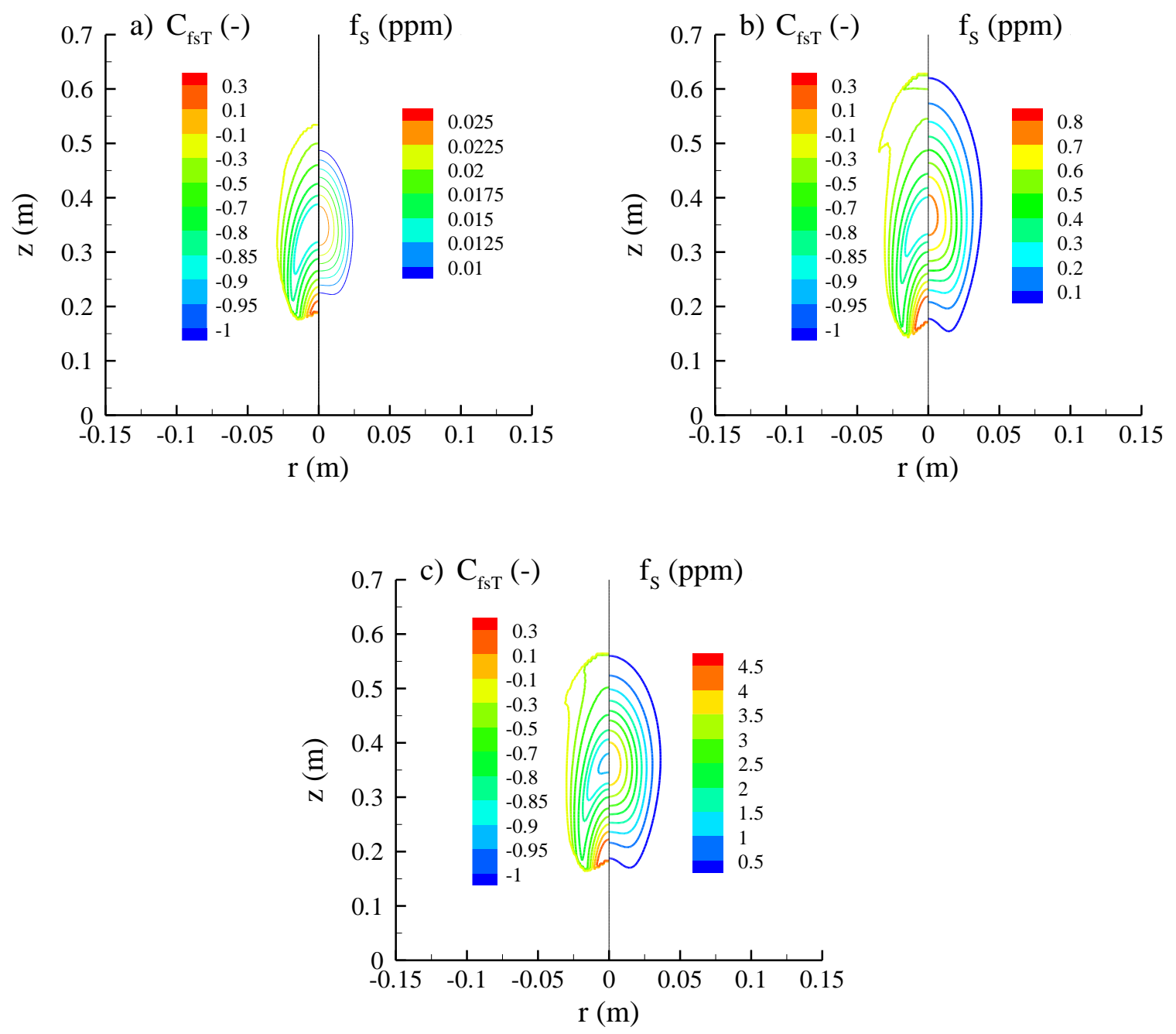

Figure 4. Fields of the correlation between soot volume fraction and temperature and of soot volume fraction for the flames at a) $1 \mathrm{~atm}$, b) $3 \mathrm{~atm}$, and c) 4 atm. For each diagram the right row corresponds to the correlation between soot volume fraction and temperature and the left row to the soot volume fraction. 

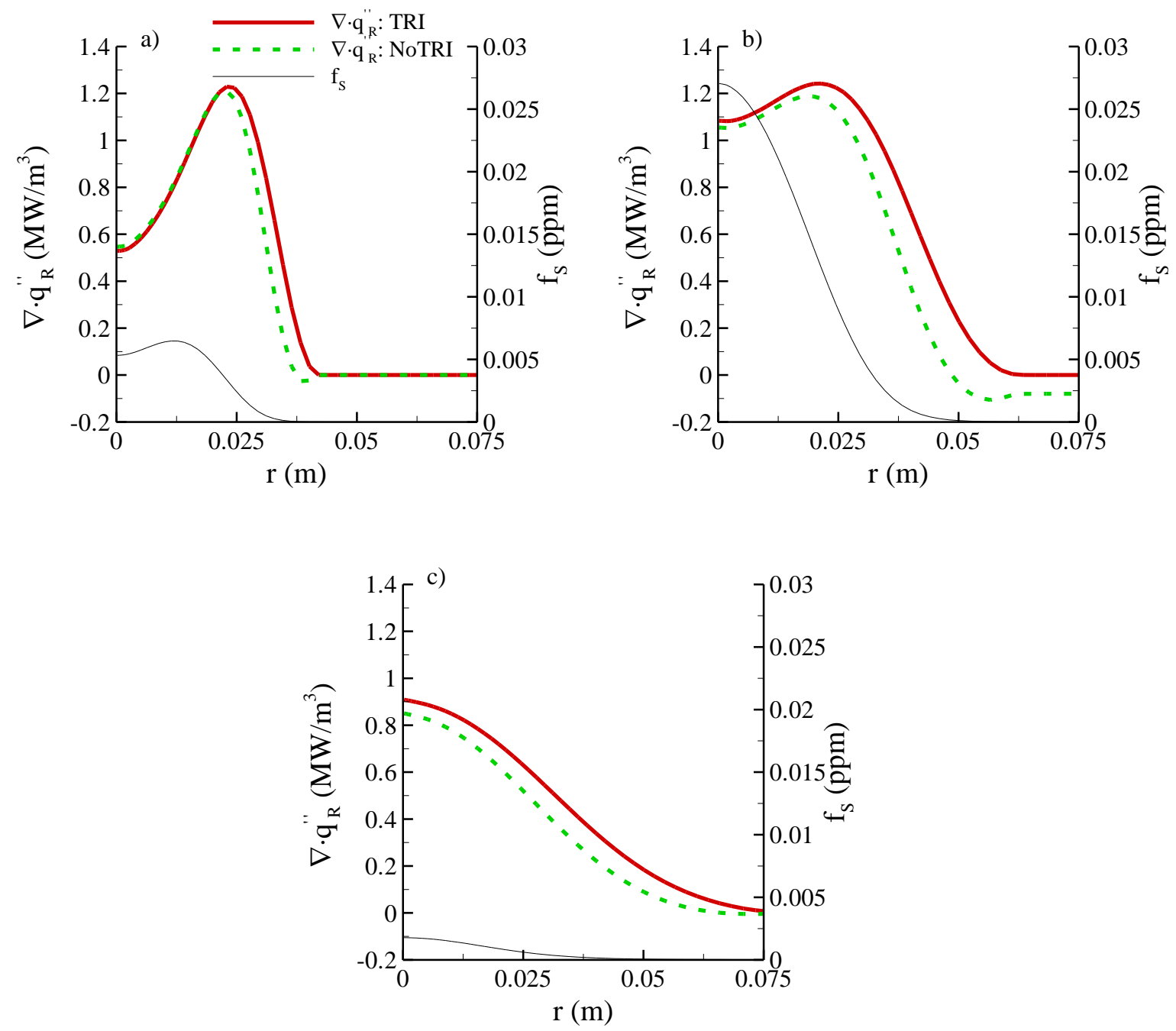

Figure 5. Effects of pressure on the radial profiles of the divergence of radiative flux for the 1 atm flame at a) $\mathrm{z}=0.2 \mathrm{~m}, \mathrm{~b}) \mathrm{z}=0.4 \mathrm{~m}$, and c) $\mathrm{z}=0.6 \mathrm{~m}$. 

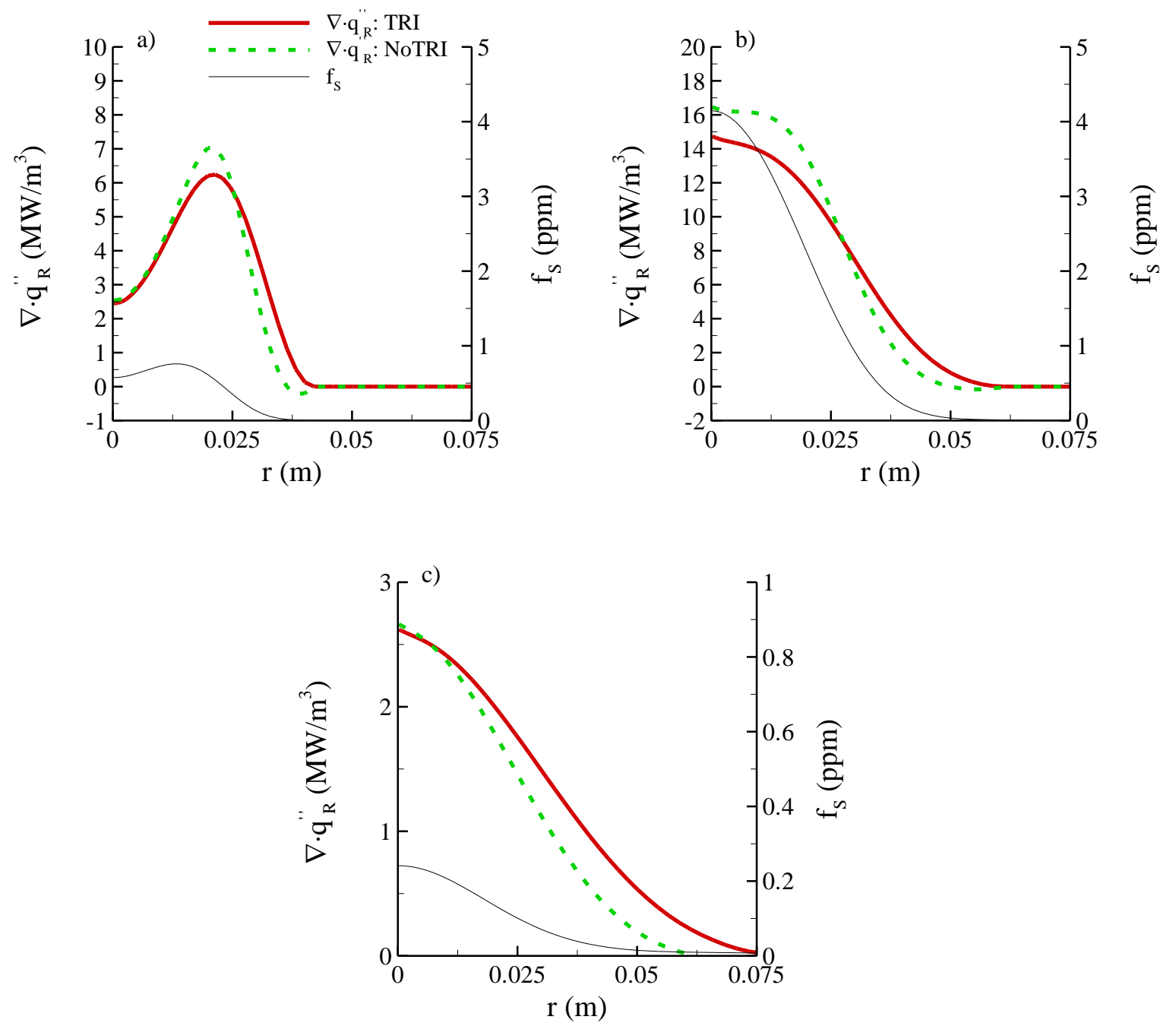

Figure 6. Effects of pressure on the radial profiles of the divergence of radiative flux for the 4 atm flame at a) $\mathrm{z}=0.2 \mathrm{~m}, \mathrm{~b}) \mathrm{z}=0.4 \mathrm{~m}$, and c) $\mathrm{z}=0.6 \mathrm{~m}$. 